\title{
Phenotypic and genetic stability of new Indonesian melon cultivar (Cucumis melo L. 'Melonia') based on ISSR markers
}

\author{
BUDI SETIADI DARYONO", APRILIA SUFI SUBIASTUTI, ARVITA FATMADANNI, DIAN SARTIKA \\ Laboratory of Genetics and Breeding, Faculty of Biology, Universitas Gadjah Mada. Jl. Teknika Selatan, Sleman 55281, Yogyakarta, Indonesia. \\ Tel.: +62-274-580839, Fax.; +62-274-6492355, ^email: bs_daryono@mail.ugm.ac.id.
}

Manuscript received: 30 September 2018. Revision accepted: 23 March 2019.

\begin{abstract}
Daryono BS, Subiastuti AS, Fatmadanni A, Sartika D. 2019. Phenotypic and genetic stability of new Indonesian melon cultivar (Cucumis melo L. 'Melonia') based on ISSR markers. Biodiversitas 20: 1069-1075. Cucumis melo L. 'Melonia' was new Indonesian melon cultivars produced by segregation of Meloni cultivar. The Meloni cultivar has a yellowish-skinned color, orange flesh fruit, and sweet taste. The stability of phenotype and genotype characters of this new cultivars were assessed using 27 morphological traits and 4 ISSR primers, respectively. Phenotype characters in $\mathrm{F}_{2}$ and $\mathrm{F}_{3}$ populations have been stable on 25 of 27 morphological traits used, except in weight of seed cavity and color of skin fruit. The 4 ISSR markers were produced 41 fragments, contained 28 monomorphic DNA bands and 13 polymorphic DNA bands. All of DNA bands were scored and used for genetic similarity analysis using MVSP 3.1A Program. The highest genetic variation was produced by UBC-808 primer with a polymorphic percentage of $38.46 \%$. All of 'Melonia' populations were clustered together with 100\% similarity percentage. Compared to other cultivars, 'Melonia' had high similarity with 'Meloni' in $87.8 \%$, meanwhile, 'Melonia' and Meloni cultivars had relationship with Melona at a similarity value of $70.7 \%$.
\end{abstract}

Keywords: Cucumis melo L. 'Melonia', molecular characters, PCR-ISSR, phenotypic characters

\section{INTRODUCTION}

Indonesia is an agricultural country that is rich in plant species. One that supports this is because Indonesia has a tropical climate. Indonesia is at latitude $7^{\circ} 02^{\prime} \mathrm{N}-11^{\circ} 15^{\prime} \mathrm{S}$ and longitude $94^{\circ} 15^{\prime} \mathrm{E}-141^{\circ} 15^{\prime} \mathrm{E}$ so that it is hot and humid throughout the year (Hall, 2009). Melon (Cucumis melo L.) is a plant that is widely grown in Indonesia, especially in the dry season. Melon is rich in nutrients, every 100 grams of fresh fruit meat contains $92.1 \%$ water, $0.5 \%$ protein, $0.3 \%$ fat, $6.2 \%$ carbohydrate, $0.5 \%$ fiber, and 350 IU vitamin A. Besides that, the economic value and promising prospects, both in the marketing of fruit and seeds, make melon as one of the fruit commodities which is a priority in the agricultural sector (Daryono and Maryanto 2017).

Plant breeding is an effort to develop improved plant cultivars suited to the needs of consumer or farmers by creating and selecting superior plant phenotypes. There are many methods for generated superior which is by crossing (conventional breeding), discovering of novel genetic variations, or identifying genotypes with superior combinations (Varshney et al. 2005; Moose and Mumm 2008). The traits of the plant are said to be superior is to have a high level of productivity, certainty of the success of the harvest, and high-quality crops (Mangoendidjojo 2010). One problem that can arise in plant breeding is variation. New cultivars must have phenotype and genotype stability as well as has unique characters that different from other cultivars have been found. Variations that appear in plants can arise as phenotypic variations or genetic variations (Maryanto et al. 2014). Phenotypic variation can be observed from morphological characters in various plant organs, while genetic variations can be identified through DNA analysis

The advances in molecular genetics have greater impact on plant breeding research. Application of molecular techniques in selection superior cultivars has shorter time consumption, less labor intensity, and increase efficiency in selection (Leng et al. 2017). Marker-assisted selection strategies have been widely used in molecular plant breeding. Molecular markers are very helpful in characterizing genetic variation and selecting superior traits, as well as distinguish between genotypes in population. Molecular markers was divided into functional markers and random markers. Functional markers are constructed from gene sequences data while random markers are generated from anonymous regions of the genome that linked to trait alleles (Varshney et al. 2005).

Because of lack of information about plant genome, random markers was widely used for fast screening of genetic variation between populations. There are many types of random markers, such as random amplified polymorphic DNA (RAPD), amplified fragment of length polymorphisms (AFLP), inter-simple sequence repeat (ISSR), microsatellite, repetitive sequence-based PCR (rep-PCR), and sequence characterized amplified regions (SCAR) (Grover and Sharma 2016). This study used random DNA markers, especially ISSR to determine genotype stability between $F_{2}$ and $\mathrm{F}_{3}$ population of 'Melonia' melon. ISSR is a genotyping technique that amplifies DNA segments between two identical microsatellites repeating regions in opposite directions ( $\mathrm{Ng}$ and Tan 2015). This technique uses micro- 
satellite with 16-25 bp long. ISSR is suitable to analyze for genetic variation because of it more reproducible than RAPD. The source of polymorphisms of ISSR is abundance and high evolutionary rate of microsatellite in individual genome as well as hypervariability either among individuals or different species (Reddy et al. 2002; Grover and Sharma 2016). Analysis of genetic variation of plant species using ISSR has been successfully done on rice (Joshi et al. 2000), Vigna (Ajibade et al. 2000), sweet potato (Huang and Sun 2000), wheat (Nagaoka and Ogihara 1997), Italian melon (Sestili et al. 2011), Cucurbita pepo (Paris et al. 2003), and chili (Thuy et al. 2016).

Melon 'Melonia' cultivar is one of the melon cultivars that are being developed by researchers at the Genetics and Breeding Laboratory, Faculty of Biology, Gadjah Mada University. Melon 'Melonia' is generated from segregation of the melon 'Meloni'. This cultivar has a phenotypic character which is oval shaped, yellow and has a sweet taste. Research on phenotypic and molecular character is carried out to support 'Melonia' to be a superior cultivar and of high selling value. The aim of this study was to determine the stability of phenotype and genotype character of the 'Melonia' melon and to reveal the 'Melonia' relationship with comparative melons, 'Meloni' and 'Melona'.

\section{MATERIALS AND METHODS}

\section{Study area}

The study was conducted in September 2017 until May 2018. Breed-stocks $\left(F_{1}\right), F_{2}$ and $F_{3}$ 'Melonia' were planted at the screen house of the Agro-technology Innovation Center (PIAT), Gadjah Mada University (UGM) in Kalitirto, Berbah, Sleman, Yogyakarta, Indonesia While molecular analysis was carried out at the Laboratory of Genetics and Breeding, Faculty of Biology, UGM, Yogyakarta, Indonesia.

\section{Planting, maintaining and retrieving phenotypic character data}

'Melonia' $\left(F_{1}, F_{2}\right.$ and $\left.F_{3}\right)$ seeds were soaked in water for one night. The seeds are germinated in wet paper and allowed to stand for 2-4 days until the radicle appears. Sprouts are moved to small polybags filled with soil for 5 days before moved into larger pots. Melon plants that have been moved into pots are watered as much as 2 dippers every 2 days. After the plant is 1 week old HST, NPK fertilizer and fungicide are given at a dose of $6.67 \mathrm{~kg} / \mathrm{ha}$. Qualitative and quantitative character observations are carried out on the land and in the laboratory based on IPGRI.

\section{DNA extraction}

As much as 0.3 grams of leaf samples were used for DNA isolation using DNA isolation kit as described by Daryono and Natsuaki (2002). Samples were ground using porcelain mortar and added $500 \mu \mathrm{L}$ of reagent $\mathrm{I}$. The mixed reagents were transferred into a $1.5 \mathrm{~mL}$ tube and added 200 $\mu \mathrm{L}$ of reagent II, continued with incubation at $67^{\circ} \mathrm{C}$ for 20 minutes and then placed in the freezer for 10 minutes.
Then, amount of $400 \mu \mathrm{L}$ of cold chloroform and $20 \mu \mathrm{L}$ of resin was added then shaked it for 30 minutes. Then centrifuged at $1300 \mathrm{rpm}$ for 10 minutes. The supernatant obtained was taken and transferred to a new tube measuring $1.5 \mathrm{~mL}$. Samples were centrifuged $1300 \mathrm{rpm}$ for 10 minutes to get supernatant. The supernatant was moved into new tube then a 1:1 cold isopropanol was added slowly through the tube wall. Then it was mixed slowly and centrifuged at a speed of $10,000 \mathrm{rpm}$ for 10 minutes. The second supernatant was removed and DNA pellets were obtained at the base of the tube. The pellets were washed with $100 \mu \mathrm{L}$ of $70 \%$ ethanol and centrifuged at $10,000 \mathrm{rpm}$ for 5 minutes. This washing was done 3 times. Ethanol was discharged from tube then dried in air. At final step, $50 \mu \mathrm{L}$ 1x TE buffer was added into tube as keeping buffer. DNA quality and concentration then were tested using Nanovue Plus Nanodrop spectrophotometer at absorbance 260/280 nm.

\section{DNA amplification using ISSR markers}

In this study, total of 4 ISSR primers was used to asses genotype stability of 'Melonia' melon. The primer sequences were described in Table 1.

Table 1. Sequences of ISSR primer used in this study (Innark et al. 2014)

\begin{tabular}{ll}
\hline Primer & Primer sequence 5'-3' \\
\hline UBC-807 & AGAGAGAGAGAGAGAGT \\
UBC-808 & AGAGAGAGAGAGAGAGC \\
UBC-811 & GAGAGAGAGAGAGAGAC \\
UBC-824 & TCTCTCTCTCTCTCTCG \\
\hline
\end{tabular}

DNA amplification was carried out using Bio-Rad T 100TM Thermal Cycler PCR. A total of $25 \mu \mathrm{L}$ PCR mix, containing $12.5 \mu \mathrm{L}$ PCR Kit ready mix $\left(\mathrm{MyTaq}^{\mathrm{TM}} \mathrm{HS}\right.$ Red Mix), $2 \mu \mathrm{L}$ DNA template (200 ng), $2 \mu \mathrm{L}$ ISSR primer (10 pmol), and $8.5 \mu \mathrm{L}$ distilled water, was used as PCR mix. The condition for PCR reaction was as follow initial denaturation at $95^{\circ} \mathrm{C}$, continued with 35 cycles of 15 seconds at $95{ }^{\circ} \mathrm{C}, 15$ seconds at $40-46{ }^{\circ} \mathrm{C}$, and 45 seconds at $72{ }^{\circ} \mathrm{C}$, then followed with final extension at $72{ }^{\circ} \mathrm{C}$ for 4 minutes. PCR amplifications then visualized using electrophoresis in $1.5 \%$ agarose gel stained with Florosafe DNA staining in $1 \mathrm{x}$ TBE buffer. Electrophoresis was done in 50 volts for 60 minutes then visualized using Geldoc UV Transilluminator.

\section{Data analysis}

Analysis of phenotypic data was separated into qualitative characters and quantitative characters. Qualitative characters were analyzed based on IPGRI while quantitative characters were analyzed with One Way Annova using PKBT-STAT-2 program (Maryanto et al. 2014).

The molecular data in the form of DNA fragments are converted into matrix $0-1$. If there was DNA band, it was written as 1 but if there were no DNA bands, it was written as 0. Cluster analysis was performed to construct dendrogram of phenetic relationship from the similarity data matrices using UPGMA method (Unweighted Pair Group Method using Arithmetic Averages). Genetic 
similarities were estimated using Jaccard's coefficient with MVSP 3.1 program.

\section{RESULTS AND DISCUSSION}

\section{The stability of phenotype character of 'Melonia' Melon}

Based on qualitative characters, 'Melonia' melon had been stable in following characters: stem color, leaf color, flower ( $\left.\delta^{A}\right)$ petals color, flower (hermaphrodite) petal color, flower $\left(\sigma^{\Uparrow}\right)$ crown color, flower (hermaphrodite) crown color, fruit shape, net, fruit flesh flavor, seed shape, seed color, texture of fruit flesh, range of fruit flesh sweetness long shelf life, and age of harvesting. However, fruit skin color and fruit flesh color has not been stable but had shown a very similar color (Table 2). 'Melonia' also shown unique characters compared to both comparative cultivars. 'Melonia' was different in stem color, sepals color (both in Male and hermaphrodite), petals color (both in Male and hermaphrodite), skin fruit color, flesh fruit color, seed color, and range of fruit flesh sweetness (Table 2). This result suggested that 'Melonia' was different cultivars with' Meloni' even though they came from same parents. Furthermore, 'Melonia' also showed different qualitative characters with 'Melona', especially in stem color, sepals color (both in Male and hermaphrodite), petals color (both in Male and hermaphrodite), fruit shape, fruit skin color, fruit flesh color, seed color, and long of shelf life. 'Melona' was characterized by a lobed fruit shape which is not found in 'Melonia' and 'Meloni' (Figure 1).

The stability of quantitative phenotype character of 'Melonia' showed that only weight of seed cavity was still unstable. This character was significantly different at the 95\% confidence level based on statistical test (Table 3).
Meanwhile compared to other cultivars, 'Melonia' was significantly different almost at all quantitative characters, except in vertical diameter and weight of skin fruit with 'Meloni' and in weight of fruit, vertical diameter, and weight of skin fruit with 'Melona' (Table 3). This results showed that 'Melonia' was unique from comparative cultivar not only qualitatively but also quantitatively.

\section{The stability of genotype character of 'Melonia' Melon}

Molecular analysis of genotype character was conducted using four ISSR primers. A total of 41 bands, of which $13(31.7 \%)$ were polymorphic. The maximum number of DNA bands was generated by UBC 808 primer (13 bands) while minimum number of DNA band was produced by UBC 811 primer ( 8 bands). Every primer was produced different pattern of DNA band, range from $250-$ 1800 bp. Based on PCR-ISSR result, UBC 807 primer (Figure 2) obtained 11 DNA bands measuring from 2601400 bp. The seven DNA bands produced were monomorphic and 4 bands at $774 \mathrm{bp}, 1146 \mathrm{bp}, 1251 \mathrm{bp}$, and $1400 \mathrm{bp}$ were polymorphic. UBC 808 primer (Figure 3) obtained 13 DNA bands range from 363-1827 bp. The eight DNA bands were monomorphic while 5 bands at 1827 bp, 1295 bp, 1257 bp, 1160 bp, and 565 bp were polymorphic. These primers produced specific band that only found on Melona cultivars at $565 \mathrm{bp}$. UBC 811 primer (Figure 4) produced 8 DNA bands range from 257-1625 bp consist of seven monomorphic DNA bands and one polymorphic DNA bands at 1625 bp. Meanwhile, UBC 824 primer (Figure 5) obtained 9 DNA bands at 511-1625 bp consist of seven monomorphic DNA bands and 3 polymorphic DNA bands at $511 \mathrm{bp}, 603 \mathrm{bp}$, and $1625 \mathrm{bp}$. A 511 bp was specifically found at Melona thus can be used to differentiate Melona from Meloni and 'Melonia' cultivars.
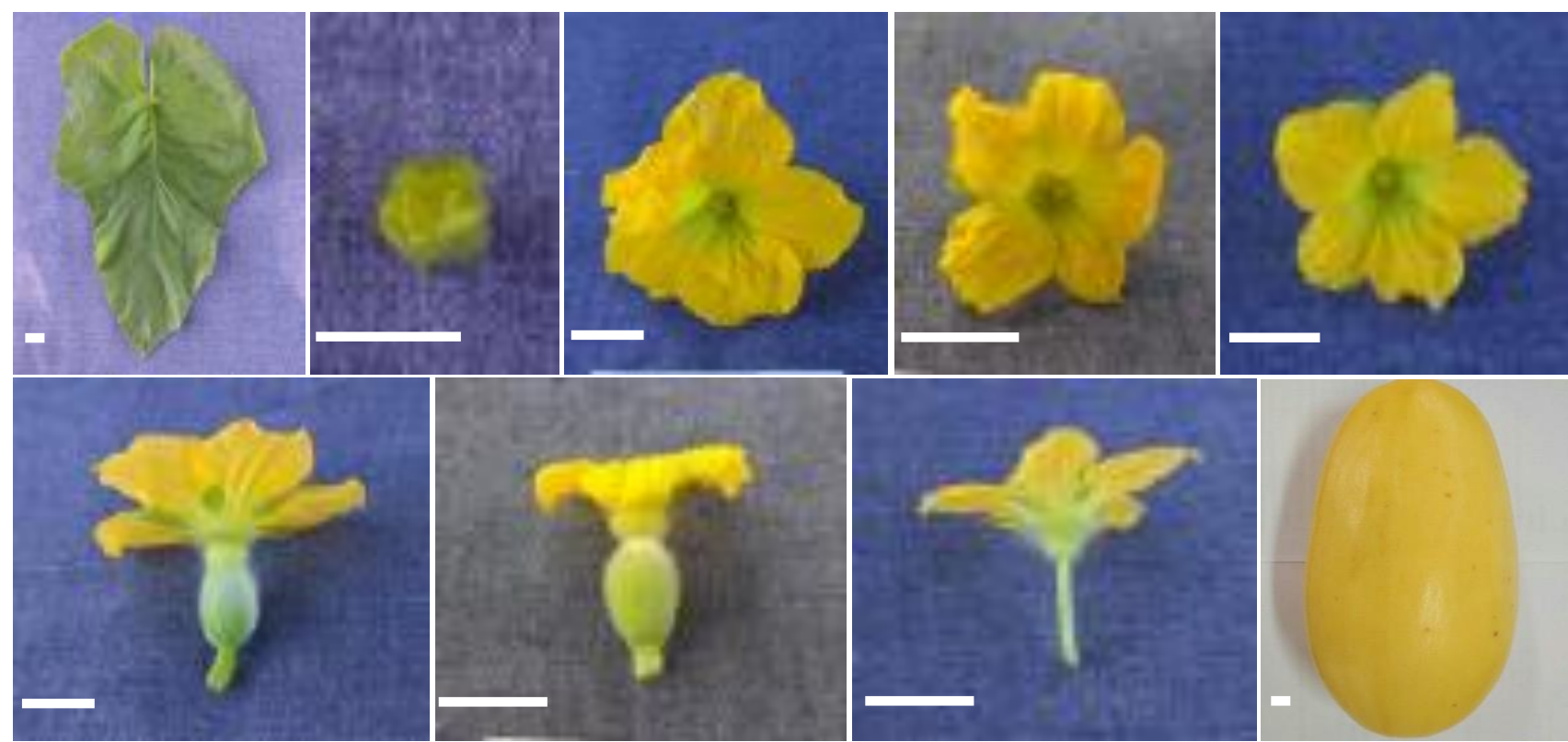

Figure 1. Phenotypic character of new Indonesian melon Cucumis melo L 'Melonia'. A. Leaf, B. Stem, C. Hermaphrodite flower, D. Female flower, E. Male flower, F. Hermaphrodite fruit, G. Female fruit, H. Male fruit, I. Mature fruit. Bar $=1 \mathrm{~cm}$. 


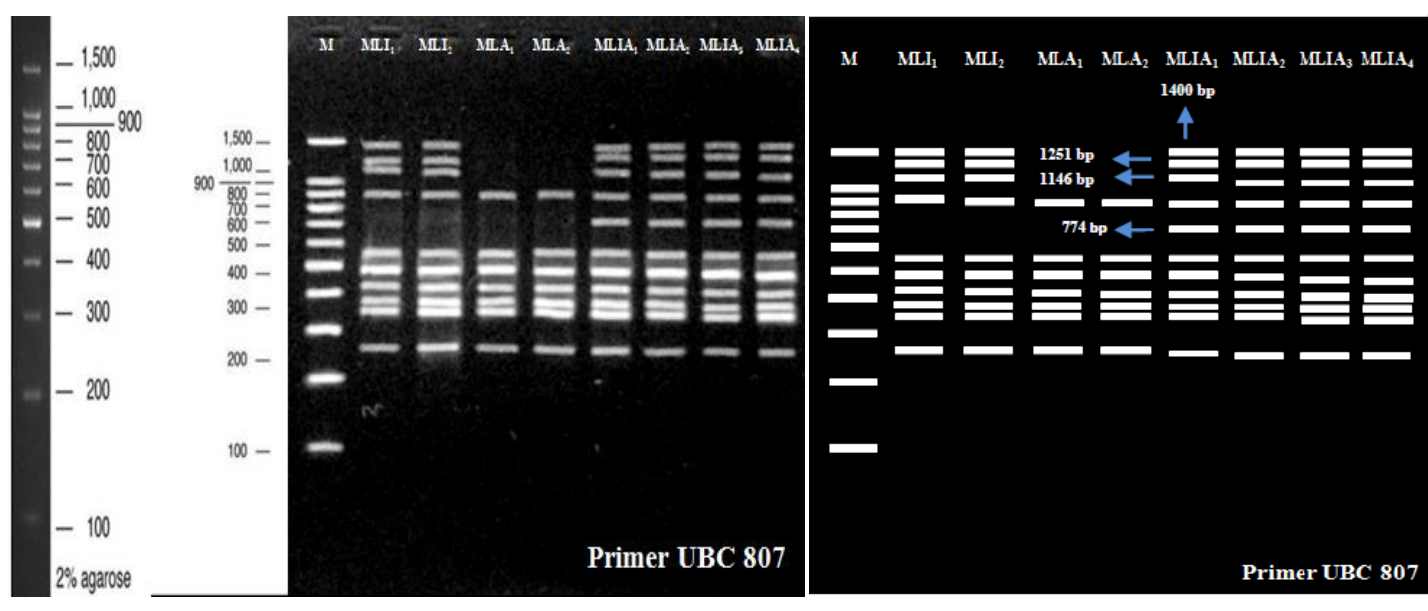

Figure 2. Amplification result of PCR-ISSR from leaves using agarose gel $2 \%$ with primer UBC 807
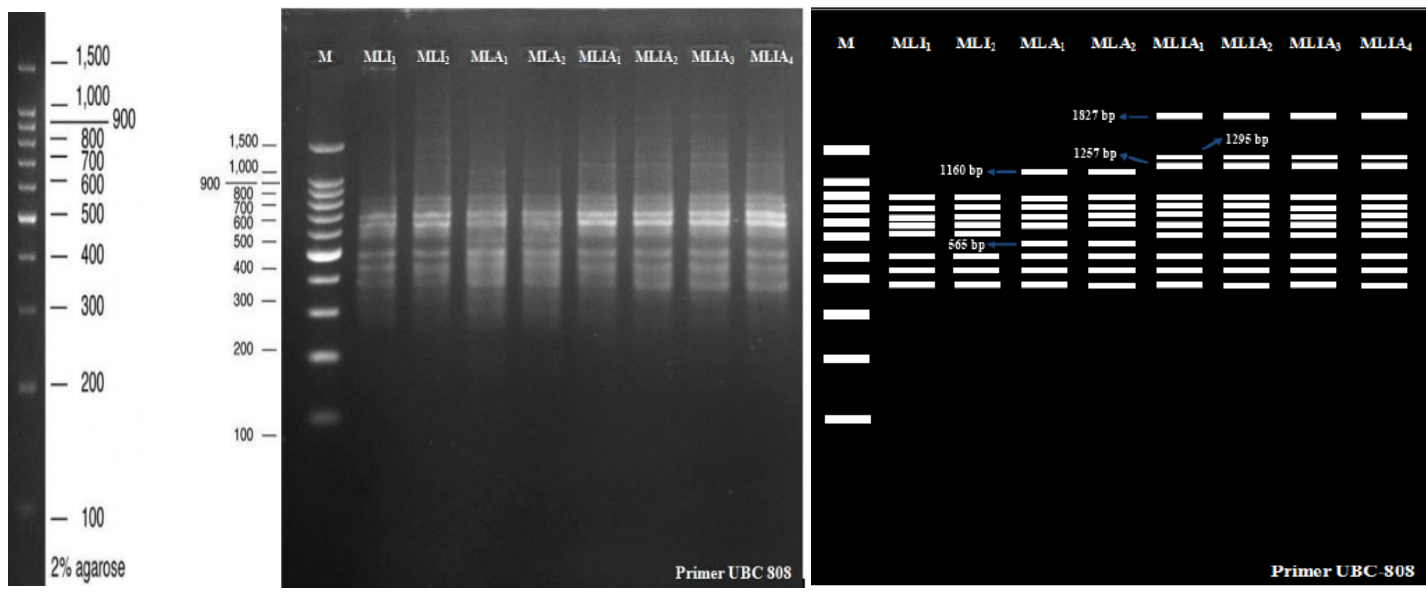

Figure 3. Amplification result of PCR-ISSR from leaves using agarose gel $2 \%$ with primer UBC 808
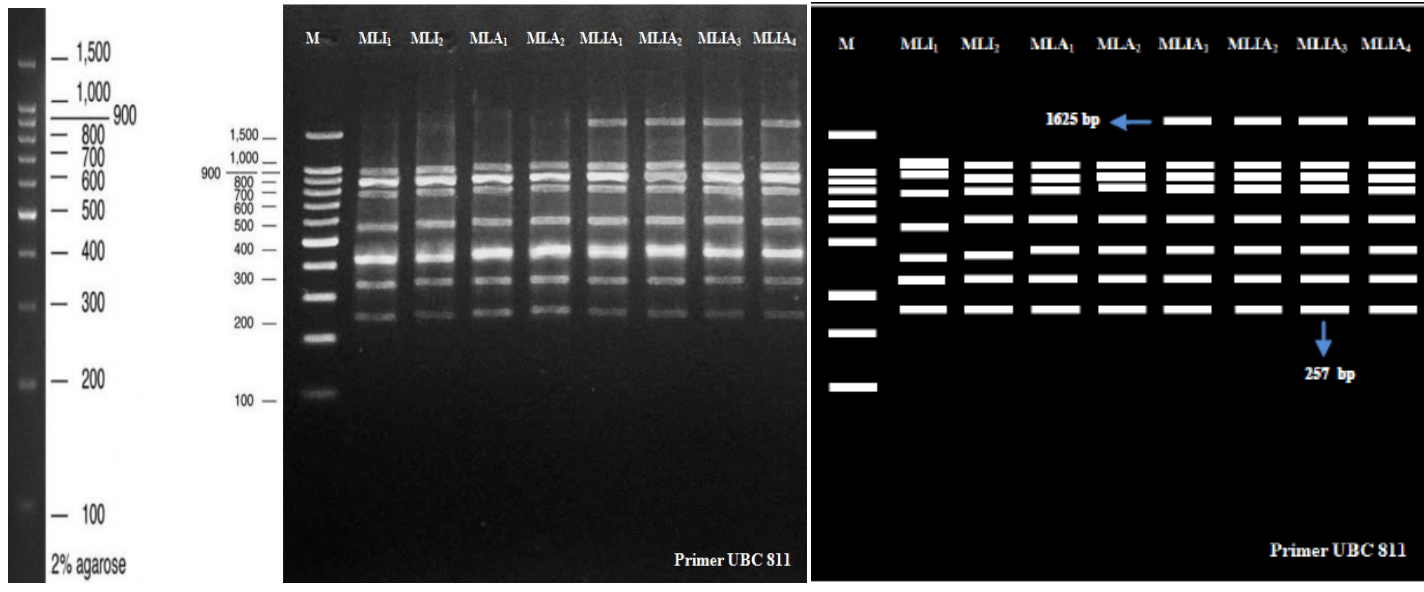

Figure 4. Amplification result of PCR-ISSR from leaves using agarose gel $2 \%$ with primer UBC 811 

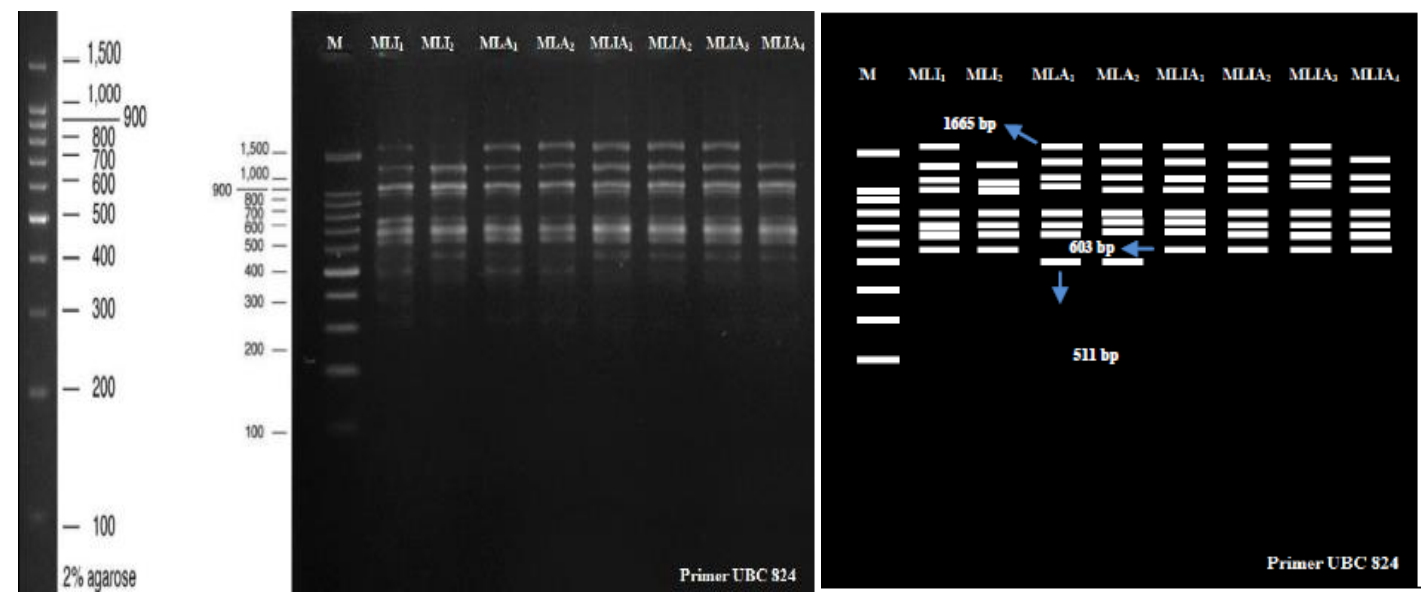

Figure 5. Amplification result of PCR-ISSR from leaves using agarose gel 2\% with primer UBC 824

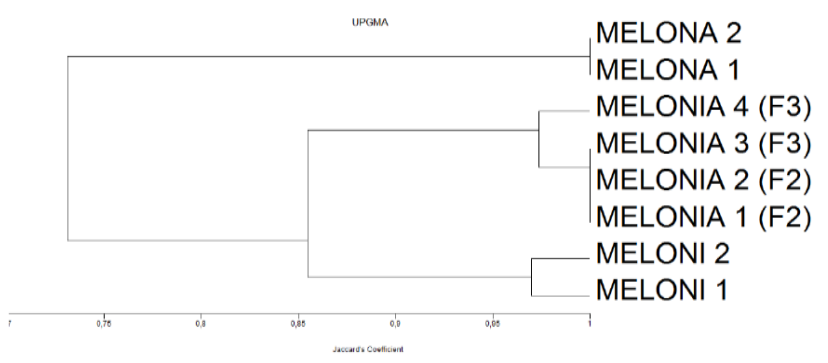

Figure 6. UPGMA dendrogram based on ISSR data showing genetic similarities between 'Melonia' melon comparative cultivars calculated with Jaccard's Coefficient

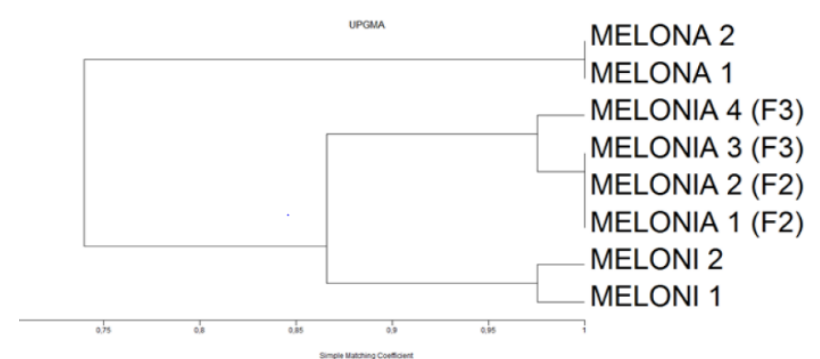

Figure 7. UPGMA dendrogram based on ISSR data showing genetic similarities between 'Melonia' melon comparative cultivars calculated with Simple Matching Coefficient

All primers showed same DNA band pattern when amplified DNA from $F_{2}$ and $F_{3}$ population of 'Melonia' cultivar but were different compared to Meloni and Melona cultivars. This was indicated that genotype of 'Melonia' cultivar has been stable. Out of 3 from 4 primers were produced specific band that only found on 'Melonia' cultivar. There were UBC 807 at 774 bp, UBC 808 at 1295 bp and $1827 \mathrm{bp}$, and UBC 811 at $1665 \mathrm{bp}$.

\section{Phenetic relationship of 'Melonia' melon based on ISSR Markers}

Based on cluster analysis using Jaccard's coefficient, there is 3 cluster that was produced. Cluster 1 is Melona, cluster 2 is Meloni, and cluster 3 is 'Melonia' (Figure 6). This dendrogram was produced according to DNA band of ISSR marker. Figure 5 showed that Meloni and 'Melonia' had $85.5 \%$ similarity while with Melona only had at $73.1 \%$ similarity. Moreover, dendrogram also showed that all 'Melonia' samples were clustered together at similarity coefficient of $97.4 \%$. The similar result was obtained from cluster analysis using the Simple Matching Coefficient, 'Melonia', 'Meloni', and 'Melonia' were separated into three clusters (Figure 7). All 'Melonia' samples showed genetic similarity at $97.6 \%$. 'Melonia' shared genetic similarity with 'Meloni' and 'Melona' at $86.6 \%$ and $74 \%$, respectively. This results suggested that 'Melonia' was different cultivars from Meloni and Melona based on ISSR markers. It was also indicated that 'Melonia' had high genotype similarity among populations as seen from similarity percentage among 'Melonia' was high ( $\geq 97 \%)$.

\section{Discussion}

The main goal of plant breeding is to develop excellent genotypes combination which has high-yield and resistance to abiotic and biotic stress. However, the goal of plant breeding has changed over the years. New superior cultivars need to achieve high yields in minimalized chemical-input systems and with the genetic diversity needed to maintain yield stability under fluctuating climatic conditions (Schmidhuber and Tubiello 2007; Heinemann et al. 2014). The crucial steps in plant breeding are selecting good parental combinations and phenotypic characters to produce superior genotypes. As described in Mendel's law of segregation that allele pairs segregate during gamete formation and randomly unite when fertilization occurs, so different parental combination could produce different phenotype variation among progeny. 'Melonia' cultivars was a new developed Indonesian melon which was generated from segregation of 'Meloni' cultivars. 'Melonia' 
was selected for further development because this cultivar was a sweetener, easier for handling, thinner fruit skin and unique (has lobe like cacao). Those characters were considered more attractive and potential for commercialization than 'Meloni'

Plant phenotype is divided into qualitative and quantitative characters. Qualitative characters are controlled by single gene so it's easier to predict the segregation patterns among progeny. Conversely, quantitative characters controlled by multiple genes and each gene have different effects on certain traits. Therefore, predictions of quantitative character segregation patterns are more difficult (Maryanto et al. 2014). Quantitative characters are strongly affected by environmental conditions. Before release to market, new cultivars not only must have superior characters but also must have phenotypic stability. As defined by Breseghello and Coelho (2013), one of the cores of breeding programs is selection of superior cultivars with desires traits until higher levels of agronomic stability, genetic uniformity, and improved adaptations. Phenotypic stability referred to the genotype to express constant phenotypes independent of different environmental conditions. Some researchers studied about effective methods to predict segregation in breeding progenies. Knowing how the population will segregate is important to choose suitable breeding methods. If the populations have begun to be stable, self-pollination could be good strategy to improve genetic uniformity, while if the populations still not expressed desired traits, back cross with certain parent could be increased the stability of those traits. 'Melonia' has planted until third generation and showed phenotypic stability among generations. Statistical results revealed that 'Melonia' has been stable in almost all characters. Furthermore, 'Melonia' also significantly different with 'Meloni' and 'Melonia'; either in qualitative or quantitative characters.

Continuous evaluation of desired traits was needed to confirm stability before new cultivar was released. A limitation of phenotypic characteristic in plant breeding is that a wide area is needed to grow and evaluate seedlings. Furthermore, this also requires a lot of labor and money. Advance in molecular biology has provided solution for this problem. DNA-based markers were widely used for genetic diversity analysis among populations or among species since it relies on genetic material and not influenced by environmental factors. The advantages of this method were highly reliable, only small sample required, stable across different developmental stage, least influenced by environmental factors and results are fast obtained (Godwin et al. 1997; Singh et al. 2016).

ISSR is multi-locus molecular marker that has been widely used for genetic diversity analysis by amplified regions between both ends of microsatellite. Genetic diversity analysis required marker which has high genetic variability and ability to generate multi-locus data so that ISSRs were suitable for this. ISSRs use microsatellites (as primers) that are highly variable and ubiquitously distributed across the genome. At the same time, ISSRs cost less and faster than AFLP and more reproducible than RAPDs (Ng and Tan 2015; Reddy et al. 2002). Genetic diversity of melon using ISSR markers has proven successful among Turkish melon (Yildiz et al. 2011), Italian melon (Sestili et al. 2011), and Indian Cucumis (Parvathaneni et al. 2011). This study also success used ISSR for genetic stability of new Indonesian melon, 'Melonia'. The amount of total bands that are produced are enough for genetic variation analysis. $\mathrm{Ng}$ and Tan (2015) described that minimal bands that are required for genetic variation is $30-50$ bands. Moreover, some primer has generated specific band that only found in 'Melonia' (UBC 808 ) and "Melona" (UBC 824) thus can be used to further develop cultivar specific marker. ISSR patterns in this study showed that the percentage of polymorphic band is below $50 \%$. However, this did not mean that the results obtained were invalid. This result actually shows that the 'Melonia' genotype had been quite stable because polymorphic bands were only seen between 'Melonia' and comparative cultivars, "Melona" and "Meloni". Although an individual comes from the same species, there are intraspecific genetic variations. But these genetic variations are generally smaller and limited than interspecies variation. Genetic variation probably due to mutation, random mating, and recombinations (Amos and Hardwood 1998; Fu 2015).

The resulting dendrograms based on the ISSR data also supported the previous result. Either dendrogram from Ssm or Jaccard coefficient shows that 'Melonia' breed generation populations were genetically uniform and stable. Both dendrograms revealed that $F_{1}, F_{2}, F_{3}$, and $F_{4}$ population of 'Melonia' had similarity index more than 97\%. The higher similarity index indicated that those individuals has close phenetic relationship and vice versa. Based on ISSR analysis, it can be suggested that 'Melonia' has higher genetic similarity with "Meloni" than "Melona". Genetic similarity is positively related to phenotypic similarity, although phenotypic expressions are also influenced by environmental conditions and genotypic and environmental interactions (Nybom 2004). It was as seen on shape and skin fruit observation. Out of 7 from 20 fruits of $F_{2}$ and $F_{3}$ populations, has perfect yellow color, while others have a yellow color that is not evenly distributed and has the same color as "Melonie (data not shown). 'Melonia' also looked more similar to "Meloni" with oval fruit shape and does not have lobes.

In conclusion, this study revealed that ISSR markers are helpful for evaluating genetic stability of new cultivars as well as for evaluating intra-species genetic variations. ISSR can be also developed as specific markers to differentiate among cultivars. The results also open new possibility to reveal the possible associations between molecular markers and phenotypic traits analyzed. Therefore, the discovery of 'Melonia' as unique cultivars of Indonesian melon has enriched Indonesian germplasm which will greatly contribute to worldwide melon plant improvement.

\section{ACKNOWLEDGEMENTS}

The authors would like to acknowledge to the Indonesian Ministry of Research, Technology, and Higher 
Education for the funding support of this research through the Development of Industrial Technology Program (Program Pengembangan Teknologi Industri-PPTI 2017).

\section{REFERENCES}

Ajibade SR, Weeden NF, Chite SM. 2000. Inter-simple sequence repea analysis of genetic relationship in the genus Vigna. Euphytica 111(1): 47-55.

Amos W, Hardwood J. 1998. Factors affecting levels of genetic diversity in natural populations. Philos Trans $\mathrm{R}$ Soc London B Biol Sci 353(1366): 177-186

Breseghello F, Coelho ASG. 2013. Traditional and modern plant breeding methods with examples in rice (Oryza sativa L.). J Agric Food Chem 61(35): 8277-8286.

Daryono BS, Maryanto SD. 2017. Keanekaragaman dan Potensi Sumber Daya Genetik Melon. Gadjah Mada University Press, Yogyakarta. pp. 1-2; 76-81. [Indonesia].

Daryono BS, Natsuaki K. 2002. Application of random amplified polymorphic DNA markers for detection of resistant cultivars of melon (Cucumis melo) against Cucurbitaceae viruses. Acta Hortic 588: 321-329.

$\mathrm{Fu}$ Y. 2015. Understanding crop genetic diversity under modern plant breeding. Theor Appl Genet 128: 2131-2142.

Godwin ID, Aitken EAB, Smith LW. 1997. Application of inter-simple sequence repeat (ISSR) markers to plant genetics. Electrophoresis 18:1524-1528.

Grover A, Sharma PC. 2016. Development and use of molecular markers: past and present. Crit Rev Biotechnol 36(2): 290-302.

Hall, R. 2009. Indonesia, Geology. In R Gillespie, D. Clague (Eds.) Encyclopedia of Islands. University of California Press. Berkeley, California,

Heinemann JA, Massaro M, Coray DS, Agapito-Tenfen SZ, Wen JD. 2014. Sustainability and innovation in staple crop production in the US Midwest. Int J Agric Sustain 12:71-78.

Huang JC, Sun M. 2000. Genetic diversity and relationships of sweet potato and its wild relatives Ipomoea series batatas (Convolvulaceae) as revealed by inter-simple sequence repeat (ISSR) and restriction analysis of chloroplast DNA. Theor Appl Genet 100(7): 1050-1060.

Innark P, Ratanachan T, Khanobdee C, Samipak S, Jantasuriyarat C. 2014 Downy mildew resistant/susceptible cucumber germplasm (Cucumis sativus L.) genetic diversity assessment using ISSR markers. Crop Prot 60: 56-61.

Joshi SP, Gupt VS, Aggarwal RK, Ranjekar PK, Brar DS. 2000. Genetic diversity and phylogenetic relationship as revealed by inter-simple sequence repeat (ISSR) polymorphisms in the genus Oryza. Theor Appl Genet 100(8): 1311-1320.

Leng P, Lubberstedt T, Xu M. 2017. Genomics-assisted breeding- A revolutionary strategy for crop improvement. J Integr Agric 16(12): 2674-2685.

Mangoendidjojo. 2010. Dasar-Dasar Pemuliaan Tanaman. Kanisius, Yogyakarta. pp 30-34. [Indonesia]

Maryanto SD, Ranis RE, Daryono BS. 2014. Stability phenotypic characters and the scent of gama melon perfume cultivar. IPTEK J Proc Ser (1): 523-528.

Moose SP, Mumm RH. 2008. Molecular plant breeding as the foundation for $21^{\text {st }}$-century crop improvement. Plant Physiol 147:969-977.

Nagaoka T, Ogihara Y. 1997. Applicability of inter-simple sequence repeat polymorphisms in wheat for use as DNA markers in comparison to RFLP and RAPD markers. Theor Appl Genet 94(5): 597-602.

Ng WL, Tan SG 2015. Inter Simple Sequence Repeat (ISSR) marker: Are we doing it right? ASM Sci J 9(1) 30-39.

Nybom H. 2004. Comparison of different nuclear DNA markers for estimating intraspecific genetic diversity in plants. Mol Ecol 13:11431155.

Paris HS, Yonash N, Potnoy V, Mozes-Daube N, Tzuri G, Katzir N. 2003. Assessment of genetic relationships in Cucurbita pepo (Cucurbitaceae) using DNA markers. Theor Appl Genet 106:971-978.

Parvathaneni RK, Natesan S, Devaraj AA, Muthuraja R, Venkatachalam R, Subramani AP, Laxmanan P. 2011. Fingerprinting in cucumber and melon (Cucumis spp.) genotypes using morphological and ISSR markers. J Crop Sci Biotech 14(1):39-43.

Reddy MP, Sarla N, Siddiq EA. 2002. Inter-simple sequence repeat (ISSR) polymorphism and its application in plant breeding. Euphytica 128:9-17.

Schmidhuber J, Tubiello FN. 2007. Global food security under climate change. PNAS 104(50): 19703-19708.

Sestili S, Giardini A, Ficcadenti N. 2011. Genetic diversity among Italian melon inodorus (Cucumis melo L.) germplasm revealed by ISSR analysis and agronomic traits. Plant Genet Resour: Characterization Util 9(2):214-217.

Singh DK, Tewari R, Singh NK, Singh SS. 2016. Genetic diversity cucumber using inter simple sequence repeats (ISSR). Transcriptomics 4(1): 1-4

Thuy VTB, Ky H, Ba TT, Hien NL, Yeap SK. 2016. Assessment of genetic diversity of chili rootstock using ISSR marker. Can Tho Univ J Sci 3:7-13.

Varshney RK, Graner A, Sorrels ME. 2005. Genomics-assisted breeding for crop improvement. Trends Plant Sci 10(12): 621-630.

Yildiz M, Ekbic E, Keles D, Sensoy S, Abak K. 2011. Use of ISSR, SRAP, and RAPD markers to assess genetic diversity in Turkish melon. Sci Hortic (Amst) 130: 349-353. 